\title{
LAS REDES DEL NARCOTRÁFICO Y SUS INTERACCIONES: UN MODELO TEÓRICO
}

Leonardo Raffo López*

José Luis Segura**

$\mathrm{E}$ ste artículo analiza las redes de vínculos sociales que forman la base estructural del narcotráfico y sus interacciones estratégicas. Examina el impacto de la densidad de esas redes en la probabilidad de supervivencia de los narcotraficantes y en otras variables relevantes. Se propone una estructura analítica de teoría de juegos y redes sociales que es útil para explicar y replicar las interacciones fundamentales entre los agentes que la producen y trafican drogas ilícitas en el contexto de redes como la del Cartel del Norte del Valle (Salazar y Restrepo, 2011), o las redes colombo-mexicanas que estudian Garay y Salcedo (2012).

El objetivo es construir un modelo que capte los rasgos esenciales de esas redes que fueron detectados y descritos en forma precisa en esos trabajos. El modelo propuesto también es útil para entender el comportamiento de redes de narcotráfico más pequeñas, fragmentadas y menos visibles como las que surgieron a mediados de los años

* Magíster en Economía, profesor asociado, miembro del Grupo de Investigación de Conflicto, Aprendizaje y Teoría de Juegos de la Universidad del Valle y del Grupo de Investigación de Desarrollo Económico, Crecimiento y Mercado Laboral de la Universidad del Valle, Cali, Colombia [leoraff@yahoo.es, leonardo. raffo@correounivalle.edu.co].

** Economista y miembro del Grupo de Investigación de Conflicto, Aprendizaje y Teoría de Juegos de la Universidad del Valle, Cali, Colombia [josesegura888@ hotmail.com]. Este artículo es un resultado del proyecto Análisis Económico del Narcotráfico entre 1990 y 2009, financiado por la Vicerrectoría de Investigaciones de la Universidad del Valle. Agradecemos los comentarios de los profesores Boris Salazar, Carlos H. Ortiz y Jaime H. Escobar a una versión anterior, así como los de dos evaluadores anónimos. Fecha de recepción: 12 de agosto de 2013, fecha de modificación: 5 de diciembre de 2014, fecha de aceptación: 29 de abril de 2015. Sugerencia de citación: Raffo L., L. y J. L. Segura. "Las redes del narcotráfico y sus interacciones: un modelo teórico", Revista de Economía Institucional 17, 32, 2015, pp. 183-212. DOI: 10.18601/01245996.v17n32.06 
noventa con la caída de los carteles de Cali y de Medellín. Se trata de un juego secuencial en dos etapas en el que los narcotraficantes y los agentes de defensa y corrupción asociados a los carteles interactúan para determinar las relaciones laborales que optimicen sus ganancias y sistemas de defensa. Cada narcotraficante mantiene un sistema de defensa para evitar ataques, delaciones, venganzas y acciones violentas de otros narcotraficantes que pueden poner en riesgo su posición en la organización y su propia vida. De ahí que la probabilidad de supervivencia de un narcotraficante en un momento dado sea un factor clave en el análisis. Pero, ¿de qué depende esa probabilidad?, ¿cuál es la incidencia de las redes de defensa y corrupción del narcotráfico en las actividades criminales? y ¿cómo inciden los cambios en las ganancias y los precios de las drogas ilegales sobre los aparatos de defensa y la probabilidad de supervivencia de los narcotraficantes organizados, y en el éxito de las políticas de represión? son algunas preguntas que intentamos responder.

En la primera sección se expone la hipótesis de base sobre la estructura y el funcionamiento de las redes de narcotráfico y en la segunda, los supuestos del modelo. En la tercera se presenta el modelo en su versión general y en la cuarta, la solución y los resultados de estática comparativa del modelo con redes regulares. En la quinta se comentan algunas predicciones del modelo y, por último, se plantean algunas conclusiones.

\section{¿CÓMO SON LAS REDES DE NARCOTRÁFICO?}

Las estructuras de las organizaciones de narcotraficantes dependen de la creación, activación, articulación, evolución y eventual destrucción de vínculos sociales que crean las condiciones necesarias para realizar una serie de transacciones sociales diversas entre las personas y grupos sociales involucrados en este tipo de negocios ilícitos.

Se propone como hipótesis que estas redes suelen estar constituidas por dos subgrafos: un subconjunto que sustenta el funcionamiento de todas las actividades de producción, distribución y comercialización de los bienes ilegales, al que llamamos redes de producción y tráfico de drogas. $\mathrm{Y}$ un subconjunto que soporta todas las actividades de seguridad y corrupción que buscan la supervivencia de la organización, y garantizan el funcionamiento de la cadena productiva al margen de la ley, al que llamamos redes de defensa y corrupción. Estos dos subconjuntos de redes sociales crean las bases sociales para el funcionamiento y la reproducción de dos tipos de tecnologías: una tecnología de producción y tráfico de drogas y una tecnología para el conflicto y la corrupción. Veamos 
en detalle en qué consisten estos dos tipos de tecnologías y las redes sociales que las soportan.

\section{LA TECNOLOGÍA DE PRODUCCIÓN Y TRÁFICO}

Esta es una cadena compleja de producción, distribución y comercialización que se puede descomponer al menos en cinco etapas: la siembra de las plantas ilícitas; la producción de las drogas y su transporte de los laboratorios clandestinos a los puertos -también clandestinosde embarque transnacional o a los mercados de consumo internos; el transporte transnacional de los países productores a los países consumidores; la distribución y comercialización en el extranjero o en el mercado interno. Y para cerrar el proceso, el lavado de activos y la reinversión de las ganancias (Mejía y Rico, 2011; Tickner et al., 2011; Duncan, 2005) $)^{1}$.

La primera y la segunda etapa se desarrollan a escala nacional en los países productores. En la primera se siembra, cosecha y recolecta el cultivo ilegal. La segunda comienza con el transporte y tratamiento de las materias primas para fabricar las drogas ilícitas, sigue con el procesamiento y la refinación de las drogas en laboratorios clandestinos, y culmina con el transporte y tráfico en el interior de los países.

La tercera y cuarta etapas se desarrollan a escala internacional, o a nivel nacional si las drogas se venden en los países productores. La tercera corresponde al transporte de estupefacientes desde los países productores hasta los países consumidores. La cuarta es el proceso de distribución al por mayor y al por menor en los países consumidores. También incluye la distribución al por mayor y al por menor en el mercado interno.

En la quinta etapa se realizan diversas transacciones que permiten el retorno de las ganancias a los narcotraficantes de alta jerarquía o a agentes ligados a ellos, quienes capitalizan y movilizan los excedentes, bien sea a través de fondos privados en paraísos fiscales, o reinvirtiéndolos en la misma u otras actividades ilícitas, o en actividades legales de lavado de activos. Un resultado importante de esta etapa es el crecimiento de la actividad ilegal, mediante reinversiones que

\footnotetext{
${ }^{1}$ Esta descripción concuerda con la de Duncan, que divide el proceso en cuatro etapas: "la siembra de coca y amapola, la transformación en drogas aptas para consumo, el contrabando a los mercados internacionales y la legalización de las ganancias" (ibíd., 23). La diferencia es que nuestra descripción divide en dos la tercera etapa de Duncan. En el caso de la cocaína, Mejía y Rico (2011) identifican siete etapas; Tickner et al. (2011) hacen una descripción más detallada en la que identifican doce eslabones en la cadena productiva del alcaloide.
} 
pueden jalonar aumentos de la productividad y de la eficiencia en las demás etapas de la cadena (Sarmiento, 1995).

En cada eslabón de la cadena intervienen varios tipos de agentes que se conectan para garantizar la producción y distribución final de la droga, cuyo valor de mercado crece exponencialmente a medida que se pasa de los primeros eslabones a los últimos. De modo que los agentes que participan en las fases finales se apropian de la mayor parte de las ganancias. En el caso de la cadena de la cocaína, por ejemplo, solo el $20 \%$ del valor agregado correspondería a 180 mil hogares cocaleros, mientras que el resto se lo apropiarían los empresarios de las fases industrial y comercial del narcotráfico (Rocha, 2011, 56 y 87; 2014).

Entre los agentes o subredes pertenecientes a las redes de producción y tráfico existe competencia económica: mientras que en los extremos de la cadena los agentes tienden a actuar en mercados competitivos -excepto en la quinta etapa, que difiere de las demás-, en las etapas intermedias la competencia es de carácter oligopólico (Duncan, 2005; Cartay, 1994; Krauthausen y Sarmiento, 1991).

En la primera etapa los productores compiten en mercados donde hay numerosos cultivadores independientes de coca, amapola o marihuana, como compiten los distribuidores y vendedores de papeletas de la cuarta etapa. En cambio, en las etapas dos y tres, los refinadores o comerciantes de pasta de coca, y los traficantes -refinadores, transportadores, y distribuidores al por mayor-, compiten en mercados casi siempre oligopólicos (Cartay, 1994) para obtener la mayor rentabilidad en la búsqueda de redes de tráfico y transporte que desemboquen más eficientemente en los mercados de alta demanda.

Algo distinto ocurre en la quinta etapa con respecto a la movilización de excedentes y lavado de activos, pues allí la competencia tiende a ser menos fuerte, y la negociación y los pactos entre rivales tienden a ser más frecuentes debido a la necesidad de ocultar y asegurar la capitalización o circulación de las ganancias. Como explica Rocha, existen diversas maneras de lavar activos, pero en la práctica la capacidad de cada organización ilegal para implementarlas está limitada por sus vínculos con el resto de la economía y guarda una relación inversa con su tamaño. "Mientras más sofisticadas y poderosas sean las organizaciones narcotraficantes, más estrechos serán sus vínculos con el resto de la sociedad, intentando de esta manera aumentar la transacción de la riqueza ilegal" (Rocha, 2000, 129).

La activación y evolución de las redes de producción y tráfico de drogas es una condición necesaria y suficiente para el funcionamiento de la tecnología de producción y tráfico de drogas, porque esas redes 
constituyen su base estructural, de modo que las redes y la tecnología se condicionan y corresponden mutuamente.

\section{LA TECNOLOGÍA PARA EL CONFLICTO Y LA CORRUPCIÓN}

Consiste en un complejo sistema de defensa y corrupción a través del cual se utilizan la fuerza, la coerción y la corrupción para defender y mantener el capital, los territorios, las redes de tráfico y transporte, y demás actividades de la cadena productiva, contra el ataque de narcotraficantes rivales $u$ otros agentes armados ilegales, y contra el control, la persecución y el juicio de las autoridades. La tecnología para el conflicto y la corrupción tiene tres componentes, los aparatos de defensa, los dispositivos de coerción y los dispositivos de corrupción.

Los aparatos de defensa garantizan la apropiación y defensa por la fuerza de las propiedades y los recursos: la tierra para sembrar los cultivos ilícitos, los territorios donde funcionan los laboratorios clandestinos, los puertos, las líneas y rutas estratégicas para el tráfico, transporte, contrabando y distribución de las drogas, y la vida de los capos, sus familiares y todo el personal contratado. Sus estructuras pueden tener diversos niveles de complejidad y sofisticación dependiendo de la oferta y la demanda de defensa de los narcotraficantes, y durante las últimas tres décadas han cambiado a medida que el negocio ha evolucionado. Pueden ser cuerpos de defensa personal integrados por escoltas y guardaespaldas, como los que mantenían durante los años setenta y ochenta; bandas de sicarios al servicio de los carteles, como las que formaron los carteles de Cali y Medellín en los años ochenta y la primera mitad de los noventa; o alianzas estratégicas con grandes grupos armados paramilitares o guerrilleros, que se hicieron más frecuentes desde comienzos de los noventa, con la entrada de lleno al negocio de las FARC y las AUC. Hoy estos aparatos de defensa dependen en mayor medida de la acción de diversos grupos armados ilegales, en particular, de bandas criminales que trabajan para narcotraficantes o en asocio con ellos. La presencia de estas bandas ha provocado una descentralización y una fragmentación mayor de las redes de producción y tráfico y de las redes de defensa y corrupción que se articulan a ellas.

Los dispositivos de coerción están ligados íntimamente a las estructuras de defensa, pero van mucho más lejos en su intención de evadir la ley y los controles sociales. Condicionan y ejercen presión sobre las autoridades, los grupos rivales y la ciudadanía a través de la fuerza y el soborno, para transgredir la ley y ejecutar acciones en su beneficio en campos relacionados con el negocio y la operación de 
las organizaciones en diferentes niveles. Se manifiestan en diversas formas: impuestos o "vacunas", extorsión, intimidación y actos terroristas, control armado, boleteo y desplazamiento forzoso.

Los dispositivos de corrupción se encargan de penetrar las estructuras políticas (locales, regionales o nacionales) mediante la cooptación de personas, grupos, organizaciones e instituciones, la compra de votos o el acceso directo a las diversas ramas del poder público, a fin de adquirir el poder suficiente para manipular la ley y las instituciones en favor de sus intereses penales, sociales, políticos o económicos. Son más sofisticados que los dispositivos de coerción y los aparatos de defensa porque ponen en juego un conjunto amplio y complejo de planes y acciones estratégicas de mediano y largo plazo que comprometen los intereses de amplios sectores de la política y la ciudadanía. Los dispositivos de corrupción se valen de los dispositivos de coerción e incluso de los aparatos de defensa para llegar a las altas esferas de gobierno, pues su meta es obtener beneficios mediante el acceso al poder y la inmunidad jurídica, sin importar los medios que utilicen. El resultado del funcionamiento continuo de estos aparatos y dispositivos es lo que Garay y Salcedo (2012) llaman Captura Avanzada del Estado y Reconfiguración Cooptada del Estado ${ }^{2}$, para quienes la Reconfiguración Cooptada del Estado (RCdE) es el resultado del proceso de penetración del Estado, las instituciones y los gobiernos que comienza con la Captura del Estado (CdE).

Siguiendo a Hellman y asociados ${ }^{3}$, Garay y Salcedo definen la CdE como "la intervención de individuos, grupos o compañías legales en la formulación de leyes, decretos, regulaciones y políticas públicas para obtener beneficios de corto y largo plazo, principalmente de naturaleza económica, en detrimento del interés público" (ibíd., 35). La RCdE es una etapa más avanzada de penetración del Estado y las instituciones en la que se supera el umbral de lo legal, y la definen como "la acción de agentes sociales legales o ilegales, que mediante prácticas ilegales o legales pero ilegítimas, buscan sistemáticamente modificar desde dentro el régimen e influir en la formulación, modificación, interpretación y aplicación de las reglas del juego social y de las políticas públicas" (ibíd.).

Los dispositivos de coerción proporcionan a las redes ilegales una facilidad para superar las fronteras de lo ilegal y acceder a lo legal (Williams, 1998, 2001). Así, los narcotraficantes amplían sus redes asociando abogados, políticos, ingenieros, banqueros y empresarios

${ }^{2}$ Las mayúsculas iniciales son de los autores.

${ }^{3}$ Hellman et al. (2000), Hellman y Kaufmann (2001) y Hellman y Kaufmann (2000). 
legales, para responder estratégicamente con mejor información y mayor capacidad de maniobra a las estrategias de control de las autoridades que intentan reprimir sus actividades.

Los componentes de la tecnología para el conflicto y la corrupción coinciden en buena medida con los requerimientos de "coerción y protección” a los que se refiere Duncan. No obstante, tratamos por aparte los dispositivos de corrupción, porque se diferencian claramente de los otros dos, surgen en etapas más avanzadas de la evolución de las organizaciones narcotraficantes y llegan a ser más complejos y sofisticados.

Pero, ¿cuál es la base estructural de esta tecnología? Su funcionamiento y reproducción es posible gracias a la activación (o desactivación), articulación y evolución de vínculos entre muchos agentes que participan de diversa manera en los aparatos de defensa o en los dispositivos de coerción y de corrupción comandados por los narcotraficantes de alta jerarquía. Estos vínculos forman las redes de defensa y corrupción, cuya configuración efectiva depende del estado concreto de la red, según sean las decisiones de los agentes conectados por ella.

Un agente puede participar en más de uno de los componentes de la tecnología para el conflicto y la corrupción, lo que genera un alto nivel de conectividad en estas redes en la medida en que existen puentes entre esos tres componentes. Igual que en el caso de la tecnología de producción y tráfico de drogas y las redes de producción y tráfico de drogas, entre la tecnología para el conflicto y la corrupción y las redes de defensa y corrupción existen relaciones de correspondencia que determinan su mutua evolución, pues estas últimas son la base estructural de la primera.

¿Quiénes participan en estas redes? Los narcotraficantes y todos los agentes que trabajan para ellos, a quienes en adelante llamamos agentes de defensa y corrupción (agentes $\mathrm{dDyC}$ ). Estos suelen realizar sus actividades de defensa, coerción y corrupción como asalariados, y se pueden catalogar como informales porque la ley y el Estado no protegen estas actividades por su ilegalidad (Martín, 2008). Martín resalta que la ilegalidad de estas actividades asalariadas nada tiene que ver con el tamaño de las organizaciones, pues son empresas que en el conjunto de toda la cadena productiva pueden tener gran escala, muchas veces de índole transnacional.

\section{LA INTERDEPENDENCIA ENTRE LOS DOS TIPOS DE TECNOLOGÍAS}

E1 carácter ilegal de las actividades de producción y tráfico de drogas, así como el carácter criminal de su venta y posesión -dependiendo 
de la legislación de cada país o Estado-, exige el desarrollo conjunto de las actividades de ambos tipos de tecnologías para la reproducción del negocio, pues son actividades complementarias que se realizan al mismo tiempo y de manera "dialéctica". Ninguna empresa ilegal puede producir, traficar y distribuir drogas ilícitas sin un sistema de defensa y corrupción que preserve la propiedad, vele por la seguridad y garantice el cumplimiento de los contratos en todos los eslabones de la cadena, no solo ante la persecución de las autoridades sino ante la acción violenta de narcotraficantes rivales. Los gastos en defensa para reducir el riesgo de incumplimiento de los contratos son evidentes en las etapas de acopio y exportación (Rocha, 2000).

Nuestra hipótesis es consistente con el análisis antropológico de Silva de Sousa (2004), para quien el funcionamiento del narcotráfico depende de tres fenómenos estructurales: uso racionalizado de la violencia ilegítima, corrupción y “valor confianza”, el cual alude a los vínculos estrechos, a veces de parentesco y amistad, que respaldan las transacciones ilegales. De acuerdo con este autor, "el uso agresivo de la fuerza física (violencia) ilegitima (desde el punto de vista estatal) es la regla, e incluso representa uno de los medios predominantes para hacer cumplir los contratos entre los agentes del sistema de comercio ilícito" (ibíd., 151, cursivas del original). Y afirma que la corrupción es un recurso para hacer cumplir los acuerdos entre los agentes del negocio ilícito, por lo que es "también otro punto diferencial en la relación social que predomina en [...] la economía ilícita y en las redes informales de transacciones económicas" (ibíd., 152).

\section{EL MODELO}

El punto de partida es la hipótesis de la sección anterior: las redes del narcotráfico tienen dos componentes: un subgrafo de producción y tráfico y otro de defensa y corrupción. Por sencillez se supone que en el primer componente solo se encuentran los productores y traficantes -a quienes llamamos narcotraficantes-, y en el segundo, diversos agentes dDyC. No obstante -como ya se advirtió-, en la realidad no es raro que algunos agentes pertenezcan al mismo tiempo a ambos tipos de redes.

Las relaciones laborales entre narcotraficantes y agentes dDyC corresponden a un tercer subgrafo: una red bipartita que muestra las interacciones estratégicas entre estos dos tipos de agentes. Se supone que los agentes $\mathrm{dDyC}$ trabajan para los narcotraficantes haciendo diferentes tareas ligadas a los aparatos de defensa, a los dispositivos de coerción, a los dispositivos de corrupción o a combinaciones de 
estos. Esto es realista, pues aunque son actividades ilegales, el trabajo en esas actividades generalmente es asalariado (Martín, 2008).

Es clave entender que las relaciones laborales entre narcotraficantes $\mathrm{y}$ agentes $\mathrm{dDyC}$ están mediadas por vínculos sociales basados en la confianza y la lealtad, de modo que aunque todos los agentes dDyC son potencialmente contratables, solo los que mantienen vínculos sociales con el narcotraficante terminan siendo sus empleados. Pero en la práctica esto no impide que un agente $\mathrm{dDyC}$ trabaje para más de un "patrón" al mismo tiempo, lo que hace posible que un narcotraficante ataque a otro por medio de uno o varios de sus hombres, es decir, que un agente $\mathrm{dDyC}$ traicione a uno de sus jefes para mejorar su situación ganando una mayor confianza de otros jefes que lo puede llevar a una mejor posición en la red criminal.

En este modelo se supone que los productores y narcotraficantes están todos conectados, de modo que las redes de producción y tráfico de drogas forman siempre una red completa. Esto es razonable en el contexto de las redes de "jerarquía agrupada" o de "grupo central" porque existen estrechas relaciones sociales entre los miembros de los grupos dominantes de las organizaciones. No obstante, ninguno de ellos suele ejercer violencia directa contra otro, sino a través de los miembros de sus sistemas de defensa y corrupción. Esto también es realista porque los traficantes usualmente delegan las acciones violentas a sus hombres - guerreros, sicarios, guardaespaldas, subordinados o militantes- aunque mantengan relaciones estrechas con sus rivales.

E1 modelo corresponde a un juego secuencial en dos etapas en el que las elecciones de los dos tipos de agentes están condicionadas por la estructura de la red existente en un momento dado. Los agentes tienen información completa y perfecta sobre la estructura de la red, la cual se supone dada. En la primera etapa cada narcotraficante interactúa con los demás fijando óptimamente el salario w (en dinero o especie) que paga a los agentes $\mathrm{dDyC}$ con quienes está conectado, pues su remuneración depende del esfuerzo que realizan. En sus decisiones, además de tener en cuenta el costo de contratación, el narcotraficante sopesa el impacto positivo de sus vínculos directos con los posibles agentes y el impacto negativo de sus vínculos indirectos con otros narcotraficantes sobre su probabilidad de supervivencia $(p)$.

${ }^{4}$ Según la UNOCD (2002) y el Observatorio del Programa Presidencial de Derechos Humanos y DIH (2006), las organizaciones criminales de "jerarquía agrupada" son una asociación de varias organizaciones criminales, coordinadas por un ente coordinador central. Cada grupo tiene estructuras particulares, pero suelen poseer las características de una "jerarquía estandarizada", la cual hace referencia a estructuras con un líder único y jerarquías estables y rigurosamente definidas. 
Sus vínculos directos con los posibles agentes $\mathrm{dDyC}$ inciden de forma positiva en $p$, porque a través de ellos él puede inducir el nivel de esfuerzo de defensa y corrupción que le proporciona seguridad, capacidad de corrupción, inteligencia logística y poder delictivo y militar. En cambio, sus vínculos indirectos con otros narcotraficantes -que corresponden a los vínculos que sus contratados tienen con otros narcotraficantes- inciden de forma negativa en $p$, porque cualquier rival puede intentar atacarlo, delatarlo, ordenar retaliaciones o asesinarlo a través de uno o varios agentes $\mathrm{dDyC}$ conectados a ambos, si tiene el poder de mando y la capacidad para ofrecer recompensas suficientes. Aunque los narcotraficantes están conectados entre sí, sus vínculos directos no inciden en su probabilidad de supervivencia. De hecho, se supone que los vínculos directos entre ellos no tienen incidencia en sus ganancias. En la segunda etapa, los agentes dDyC determinan el nivel de esfuerzo que realizan para uno o varios narcotraficantes, según el salario que reciban de cada patrón.

En su estructura secuencial este modelo se inspira en el modelo de torneos e incentivos laborales de Lazear y Rosen (1981). Puesto que los "narcotraficantes" actúan estratégicamente como líderes en la primera etapa y los agentes $\mathrm{dDyC}$ como seguidores en la segunda etapa, replica mejor las interacciones estratégicas típicas entre narcotraficantes y agentes $\mathrm{dDyC}$ de los grandes carteles que dominaron el negocio en el periodo "clásico" del narcotráfico en Colombia, los de Cali y Medellín (Tickner et al., 2011), de los grandes carteles que se formaron después, como el del Norte del Valle, o de los carteles de Juárez y Sinaloa en México, en los que es indudable la subordinación de las estructuras de defensa y corrupción al accionar de los grandes traficantes y productores. El modelo también es útil para replicar las interacciones entre narcotraficantes y agentes $\mathrm{dDyC}$ que se empezaron a gestar en la segunda mitad de los noventa con el desmantelamiento de los carteles de Medellín y de Cali; en las que, como señala Duncan (2005), las estructuras de producción y tráfico de nuevos empresarios - pertenecientes a organizaciones más pequeñas y menos visibles- comenzaron a subordinarse a las estructuras de defensa - de "coerción y protección” en los términos de este autor- comandadas por guerreros.

\section{SUPUESTOS}

\section{Las redes}

Sea $N=\{1,2, \ldots n\}$ el conjunto de narcotraficantes y agentes dDyC de la red. El grafo de toda la red se denota $(N, V)$, donde $N$ es el conjunto de 
nodos de la red y $V$ el conjunto de vínculos entre ellos (en adelante se denota como g). Cuando un par de agentes $i$ y $j$ están conectados, $g_{i j}=1$, de lo contrario están desconectados y $g_{i j}=0$. Por convención se supone que $g_{i j}=0$ y que los vínculos son recíprocos, de modo que $g_{i j}=g_{j i}, \forall \mathrm{i}, \forall \mathrm{j} \in \mathrm{g}$.

Es conveniente definir una partición $N=\left\{N_{T}, N_{D}\right\}$ que separa el subconjunto de narcotraficantes del conjunto de agentes $\mathrm{dDyC}$, donde $N_{T}=\left\{1,2, \ldots n_{T}\right\}$ es el conjunto de narcotraficantes y $N_{D}=\left\{1,2, \ldots n_{D}\right\}$ el de agentes dDyC. Se supone que $n_{T} \geq 1$ y que $n_{D} \geq 2$ de modo que $n \geq 3$. Sea $\left(N_{T}, V^{T}\right)$ el subgrafo que representa las relaciones sociales de los narcotraficantes entre sí, y que se denota como $\mathrm{g}^{T}$. Como ya se señaló, este corresponde generalmente a un grafo completo, un clique, de modo que $\forall i, \forall k \in g^{\mathrm{T}}, g_{i k}=1$ Formalmente, $g^{T}=\left\{i k \in g \mid i \in N_{T} \wedge k \in N_{T}\right\}$. Sea $N_{i}\left(g^{T}\right)=$ $\left\{k: g_{i k} \in g^{T}\right\}$ la vecindad del narcotraficante $i$ en $\mathrm{g}^{T}, \mathrm{y} d^{T}\left(\mathrm{~g}^{T}\right)$ su grado en $\mathrm{g}^{T}$. Si este subgrafo constituye un clique, $d_{i}^{T}=n_{T}-1 \geq 1, \forall i \in N_{T}$. Como $\mathrm{g}^{T}$ es una red completa, esta no incide en las ganancias de ninguno de los agentes.

Por su parte, $\left(N_{D}, V^{D}\right)$ es el subgrafo que representa las relaciones sociales de los agentes $\mathrm{dDyC}$ entre sí, y que se denota como $\mathrm{g}^{D}$. Así, si el agente $\mathrm{dDyC} j$ está conectado con un agente $\mathrm{dDyC} l$ $g_{j l}=1$; en caso contrario $g_{j l}=0$. Formalmente, $\mathrm{g}^{D}=\left\{j l \in \mathrm{g} \mid j \in N_{D} \wedge l \in N_{D}\right\}$. Sea $N_{j}\left(\mathrm{~g}^{D}\right)=\left\{l: g_{j l} \in \mathrm{g}^{D}\right\}$ la vecindad del agente $\mathrm{dDyC} j$ en $\mathrm{g}^{D}, \mathrm{y} d^{D}\left(\mathrm{~g}^{D}\right)$ su grado en $\mathrm{g}^{D}$. Se supone que cada $j$ está conectado al menos con otro $l$, pero no se excluye el caso en que no tenga ninguna conexión en $\mathrm{g}^{D}$, de modo que $d_{J}^{D} \geq 0, \forall j \in N_{D}$.

$\left(\left\{N_{T}, N_{D}\right\}, V^{b}\right)$ es el grafo bipartito que describe las relaciones sociales entre narcotraficantes y agentes dDyC. Este subgrafo se denota como $\mathrm{g}^{b}$. Si un narcotraficante $i$ está conectado con un agente $\mathrm{dDyC} j, g_{i j}=1$; en caso contrario $g_{i j}=0$. Formalmente, $\mathrm{g}^{b}=\left\{i, j \in \mathrm{g} \mid i \in N_{T} \wedge j \in N_{D}\right\}$.

Sea $N_{j}\left(\mathrm{~g}^{b}\right)=\left\{i: g_{i j} \in g^{b}\right\}$ la vecindad del agente $\mathrm{dDyC} j$ en $\mathrm{g}^{b}, \mathrm{y} d^{b}\left(\mathrm{~g}^{b}\right)$ su grado en la red bipartita. Se supone que cualquier agente dDyC está conectado con al menos un narcotraficante, de modo que $d_{j}^{b} \geq 1, \forall j$ $\in N_{D}$. Por otra parte, sea $N_{i}\left(\mathrm{~g}^{b}\right)=\left\{\mathrm{j}: g_{i j} \in \mathrm{g}^{b}\right\}$ la vecindad del narcotraficante $i$ en $\mathrm{g}^{b}$, y $d_{i}^{b}\left(\mathrm{~g}^{b}\right)$ el grado de $i$ en la red bipartita; se supone que cada narcotraficante está conectado con al menos un agente $\mathrm{dDyC}$, de modo que $d_{i}^{b} \geq 1, \forall i \in N_{T}$

\section{Los agentes y sus interacciones}

Se supone que toda la cadena productiva de las actividades ilícitas está al mando de los narcotraficantes. La función de ganancias esperadas que un narcotraficante $i$ maximiza en la primera etapa está dada por: 
$E\left[\pi_{i}\left(w_{i}, \mathrm{e}_{i}, \mathrm{e}_{-i}, \mathrm{~g}\right)\right]=p\left[(1-z) P_{D} q_{i}-s l_{i}-\underset{j \in N_{D}}{e_{j i}} g_{i j}\right]+(1-\mathrm{p})\left[-w_{j} \sum_{j \in N_{D}} e_{j i} g_{i j}\right]$

donde $p$ es la probabilidad de supervivencia del narcotraficante, $y(1-p)$ la probabilidad de ser asesinado; $p_{D}$ es el precio de las drogas ${ }^{5}$, que se supone dado; $q_{i}$ es la cantidad de drogas que vende $i ; s$ es el salario que paga a los trabajadores que laboran directamente en la producción de estupefacientes en cualquier eslabón de la cadena, y también se supone dado; $l_{i}$ es la cantidad total de trabajadores "productivos" que contrata $i^{6}$. La variable $z$ es la probabilidad de interdicción y destrucción de las drogas; el gobierno controla esta variable de política y se supone exógena. En consecuencia, 1- z es la proporción de producción ilícita que sobrevive a las políticas de represión y, en particular, de interdicción y destrucción de drogas. La razón por la que $p_{D} \mathrm{y} s$ se suponen dados es que es razonable considerar que la estructura mercantil de estos mercados -ligada a la tecnología de producción y tráfico de drogas- es competitiva y tiene barreras a la entrada (Ortiz, 2002, 2003, 2009; Raffo, 2010).

Por otro lado, $w_{i}$ denota el salario que $i$ paga a los agentes $\mathrm{dDyC}_{j}$ que contrata ${ }^{7}$; $\mathrm{e}_{i}$ es el vector $\mathrm{e}_{i}=\left(e_{1 i}, e_{2 i}, \ldots, e_{n_{d}}\right)$ del nivel de esfuerzo de cada agente contratable para un narcotraficante, de modo que $e_{j i} g_{i j}$ capta el esfuerzo realizado por $j$ para $i$, dada la posible existencia de un vínculo social entre $i$ y el agente $\mathrm{dDyC} j$; en consecuencia, si $g_{i j}=1$ se activa un vínculo laboral entre $i$ y $j$, en caso contrario $g_{i j}=0$. Aquí, $e_{-i}$ $=\left(e_{1-i}, e_{2-i}, \ldots, e_{n_{d^{-i}}}\right)$ es el vector del nivel de esfuerzo de los agentes $\mathrm{dDyC}$ para los demás narcotraficantes. Aunque estos niveles de esfuerzo no aparecen explícitamente en la función de ganancias de los narcotraficantes, como se verá más adelante, $p$ depende de estos.

La expresión $\left[(1-z) P_{D} q_{i}-s l_{i}-w_{i} \sum_{i \in N} e_{i j} g_{i j}\right]$ representa las ganancias de un narcotraficante (netas de represion) en caso de seguir vivo y no ser eliminado por algún agente $\mathrm{dDyC} ;\left[-w_{i j \in N_{b}} e_{j i} g_{i j}\right]$ representa las pérdidas que obtendría de ser eliminado. Los costos en trabajo "productivo", $s l_{i}$, no entran en el costo esperado de ser eliminado, $(1-p)\left[-w_{i} \sum_{j \in N_{i}} e_{j i} g_{i j}\right]$, porque el modelo se limita a las decisiones de defensa y corrupción.

En este modelo no se analizan las decisiones de producción, como se hace en otros trabajos, sino las transacciones laborales básicas para el funcionamiento de la tecnología para el conflicto y la corrupción (en adelante tecnología $\mathrm{pCyC}$ ) del narcotráfico. Por ello, en la función de

\footnotetext{
${ }^{5}$ Se puede interpretar como su precio al por mayor en los grandes centros de consumo.

${ }^{6}$ Se podría suponer que cada uno de ellos invierte una hora de trabajo productivo.

7 En este caso, $s$ y $w_{i}$ se pueden pagar en unidades monetarias o en especie; en el modelo se miden en unidades monetarias.
} 
producción de drogas que determina $q_{i}$ no se incluyen las elecciones de demanda de trabajo productivo ni el efecto directo del aparato de defensa. Es decir, no se modela la lucha por el dominio de la tierra entre los narcotraficante y el gobierno -como en Mejía y Grossman (2005) o Mejía y Restrepo (2008) - ni la de los narcotraficantes entre sí -como en esos mismos trabajos y en Raffo (2010)-. Por ello, se supone que el término $(1-z) P_{D} q_{i}-s l_{i}$ está dado para cada narcotraficante. Como es un mercado competitivo en su componente productivo, se puede suponer que este término -que representa el beneficio neto de la producción de drogas (sin descontar los costos de defensa y corrupción) - es idéntico para todos los narcotraficantes, de modo que $(1-z) P_{D} q_{i}-s l_{i}=(1-z) P_{D} q-s l=\bar{\pi}\left(z, P_{D}\right), \forall i \in N_{T}$.

Dados los altos márgenes de rentabilidad del negocio en la parte productiva, se supone que $\bar{\pi}>0, \forall i \in N_{T}$. Esto también ha sido probado en otros trabajos. Reordenando términos, (1) se puede reescribir así:

$E\left[\pi_{i}\left(w_{i}, \mathrm{e}_{i}, \mathrm{e}_{-i}, \mathrm{~g}\right)\right]=p \bar{\pi}\left(z, P_{D}\right)-w_{i} \sum_{j \in N_{D}} e_{j i} g_{i j}$

De (2) se infiere que los narcotraficantes obtendrán ganancias esperadas positivas si y solo si el beneficio neto esperado de la producción de drogas, $p \bar{\pi}\left(z, P_{D}\right)$, es mayor que los costos en defensa y corrupción, $w_{i} \sum_{j \in N} e_{j i} g_{i j}$.

La probabilidad de supervivencia de $i$ depende en forma directamente proporcional de los vínculos que los narcotraficantes poseen con los agentes $\mathrm{dDyC}$, e inversamente de los vínculos que estos últimos tienen con otros narcotraficantes. Utilizando un esquema inspirado en el que utilizan Calvó-Armengol y Zenou (2004) y Ballester et al. $(2006,2009)$ para modelar la probabilidad de captura de un delincuente, se supone que la probabilidad de supervivencia del narcotraficante $i$ se define como:

$p\left(\mathrm{e}_{i}, \mathrm{e}_{-i}, \mathrm{~g}\right)=p_{0}\left(\sum_{j \in N_{D}} e_{j i} g_{i j}\right)\left(1-\sum_{j \in N_{D}} \sum_{k \neq j} \delta e_{j k} g_{k j} g_{i j}\right)$

El término $\left(\sum_{j \in N_{b}} e_{j i} g_{i j}\right)$ es la sumatoria del nivel de esfuerzo de los agentes dDyC contratados por $i$, e incide positivamente en $p$, porque capta todos los posibles esfuerzos de defensa y corrupción que se pueden poner al servicio de $i$. En cambio, $\sum_{j \in N_{k}} \sum_{k \neq j} \delta e_{j k} g_{k j} g_{i j}$ capta el impacto negativo sobre $p$ de los vínculos de los agentes contratados con otros narcotraficantes, pues estos son posibles trayectorias a través de las que $i$ puede ser atacado por los demás narcotraficantes -a través de sus propios hombres-. El término $\delta$ refleja la capacidad de la tecnología 
pCyC de $i$ para defenderse de esos posibles ataques, y es un parámetro que representa el nivel de desarrollo de toda la tecnología pCyC para evitar, repeler y neutralizar los ataques de los narcotraficantes entre ellos mismos. En la forma en que se ha definido, esta probabilidad y sus posibles configuraciones de equilibrio son una manera de representar la tecnología pCyC de cada narcotraficante.

Por otra parte, $p_{0}$ es un parámetro que escala la probabilidad de supervivencia de $i$; como $0 \leq p \leq 1$ para cualquier estructura de la red $\mathrm{g}$, se debe cumplir:

$\forall i \in N_{T}, 0 \leq p_{0} \leq \frac{1}{\sum_{j \in N_{0}} e_{j i} \cdot g_{i j}}$

Así mismo, para cualquier estructura de la red g se debe cumplir:

$\forall i \in N_{T}, 0 \leq \delta \leq{\frac{1}{\sum_{j \in N_{0}} \sum_{k \neq i} e_{j k} \cdot g_{k j} \cdot g_{i j}}}^{8}$

La función de ganancias de los agentes dDyC está dada por:

$E\left[\pi_{J}\left(\mathrm{e}_{j}, \mathrm{w}, \mathrm{g}\right)\right]=\sum_{i \in N_{T}} w_{i} e_{j i} g_{i j}-\sum_{i \in N_{T}} c_{j i}\left(e_{j i}\right) g_{i j}$

Aquí $e_{j}=\left(e_{j 1}, e_{j 2}, \ldots, e_{j n_{T}}\right)$ es el vector del nivel de esfuerzo que $j$ realizaría para cada narcotraficante con el que tiene vínculos, $\mathrm{y} w=\left(w_{1}, w_{2}, \ldots\right.$, $\left.w_{n_{1}}\right)$ el vector de salarios pagados por cada narcotraficante. El primer término de la derecha de (6) representa los posibles ingresos salariales de $j$ por trabajar para los distintos narcotraficantes. Cada narcotraficante $i$ fija un salario específico $w_{i}$ a todos sus agentes. El segundo término representa los costos derivados del nivel de esfuerzo realizado para cada "jefe". Las funciones de costos de $j$ por el esfuerzo realizado para cada narcotraficante difieren entre sí; y se suponen crecientes y convexas: $c_{j i}^{\prime}\left(e_{j i}\right)>0$ y $c_{j i}^{\prime \prime}\left(e_{j i}\right) \geq 0, \forall j \in N_{D}, \forall i \in N_{T}$ Por sencillez y sin pérdida de generalidad se supone que son del tipo:

$c_{j i}\left(e_{j i}\right)=\frac{\left(n_{D}-1\right)}{d_{j}^{D}}$

El término $\frac{d_{j}^{D}}{\left(n_{D}-1\right)}$ representa la centralidad de grado del agente dDyC $j$ en la red $\mathrm{g}^{\mathrm{D}}$.

El impacto negativo de la centralidad de grado de $j$ en $c_{j i}\left(e_{j i}\right)$ obedece a que cuantos más vínculos tiene un agente $\mathrm{dDyC}$ con otros agentes dDyC más productivo es su trabajo y, por ello, menos costoso es el esfuerzo que debe hacer al trabajar para un narcotraficante. Este se puede pensar como una externalidad positiva derivada de la centra-

${ }^{8}$ De no cumplirse estas dos condiciones la probabilidad podría no estar entre 0 y 1. 
lidad, jerarquía o conectividad de ese agente dDyC con otros agentes $\mathrm{dDyC}$ en su red de contactos, o sea en $\mathrm{g}^{D}$.

\section{SOLUCIÓN GENERAL}

Como es un juego secuencial con información perfecta entre las etapas de la secuencia, se resuelve por inducción hacia atrás comenzando por la segunda etapa, donde los agentes dDyC eligen niveles de esfuerzo óptimos para cada uno de sus vínculos laborales conociendo las elecciones óptimas tomadas por los narcotraficantes en la primera etapa.

$\mathrm{E} 1$ problema que resuelve un agente $\mathrm{dDyC}$ en esta etapa es:

$\max _{e_{j i}} \pi_{J}\left(\mathrm{e}_{j}, \mathrm{w}, \mathrm{g}\right)=\sum_{i \in N_{T}} w_{i} e_{j i} g_{i j}-\sum_{i \in N_{T}}\left(\left(n_{D}-1\right) / d_{j}^{D}\right) e_{j i}^{2} g_{i j}$

De las condiciones de primer orden se deduce la oferta de esfuerzo potencial del agente $\mathrm{dDyC} j$ para cada narcotraficante $i$ en función del salario nominal:

$$
e_{j i}=\left\{\begin{array}{ccc}
\frac{d_{j}^{D} w_{i}}{2\left(n_{D}-1\right)} & \text { si } & g_{i j}=1 \\
0 & \text { si } & g_{i j}=0
\end{array}, i=1,2, \ldots, n_{T} ; j=1,2, \ldots, n_{D}\right.
$$

Se trata de una función de reacción, puesto que el narcotraficante $i$ elige $w_{i}$ en la primera etapa; (9) revela que el nivel de esfuerzo potencial óptimo de $j$ depende en forma positiva de $w_{i}$, ya que $\frac{\partial e_{i}}{\partial w_{i}}>0$ Esta variable también depende positivamente de la centralidad de grado de $j$ en $\mathrm{g}^{D}$.

En la primera etapa los narcotraficantes eligen los salarios óptimos que pagan a los agentes $\mathrm{dDyC}$ conociendo las funciones de reacción de estos en la segunda etapa. Con (3) y (9) su problema es entonces: $\max _{w_{i}} E\left[\pi_{i}\right]=\bar{\pi} \cdot p_{0}\left(\frac{w_{i}}{2}\right)\left(\sum_{j \in N_{D}}\left(\frac{d_{j}^{D} g_{i j}}{\left(n_{D}-1\right)}\right)\right)\left(1-\sum_{j \in N_{D}} \sum_{k \neq i} \delta\left(\frac{w_{k} d_{j}^{D} g_{k j} g_{i j}}{2\left(n_{D}-1\right)}\right)\right)-\frac{w_{i}^{2}}{2} \sum_{j \in N_{D}}\left(\frac{d_{j}^{D} g_{i j}}{\left(n_{D}-1\right)}\right)$

Se puede probar que las funciones de ganancias de los narcotraficantes son cóncavas en $w_{i}$ y que dependen inversamente de los salarios fijados por los demás narcotraficantes.

Para hallar el equilibrio de Nash perfecto de subjuego se resuelve el problema de elección de todos los narcotraficantes. Así se obtiene el siguiente sistema de ecuaciones lineales, cuya solución resuelve el modelo:

$$
\begin{gathered}
w_{1}^{*}=\frac{p_{0} \bar{\pi}}{2}\left(1-\sum_{j \in N_{D}} \sum_{k \neq 1} \delta\left(\frac{w_{k} d_{j}^{D} g_{1 j} g_{i j}}{2\left(n_{D}-1\right)}\right)\right) \\
w_{2}^{*}=\frac{p_{0} \bar{\pi}}{2}\left(1-\sum_{j \in N_{D}} \sum_{k \neq 2} \delta\left(\frac{w_{k} d_{j}^{D} g_{2 j} g_{i j}}{2\left(n_{D}-1\right)}\right)\right) \\
\vdots
\end{gathered}
$$




$$
w_{n_{T}}^{*}=\frac{p_{0} \bar{\pi}}{2}\left(1-\sum_{j \in N_{D}} \sum_{k \neq n_{T}} \delta\left(\frac{w_{k} d_{j}^{D} g_{n_{T} j k j} g_{i j}}{2\left(n_{D}-1\right)}\right)\right)
$$

Cada una de las ecuaciones de (11) representa la función de reacción de $i$ a los salarios fijados por los demás narcotraficantes. Esto muestra que en la primera etapa los narcotraficantes interactúan entre sí en un subjuego simultáneo con información imperfecta. En su forma general no es posible hallar una solución analítica compacta del sistema sin conocer la estructura concreta de la red; por ello en la siguiente sección se examina la solución del modelo con redes regulares. La solución analítica con redes irregulares es difícil de obtener ${ }^{9}$.

\section{SOLUCIÓN CON REDES REGULARES}

En estas redes todos los agentes tienen el mismo número de vínculos. Aunque es un caso estilizado con agentes representativos, en el que no se pueden analizar los efectos de las diferencias en la jerarquía o en el grado de centralidad de cada agente, sí se puede analizar el efecto agregado de los niveles de densidad media de las redes en equilibrio. Además, el modelo se puede resolver completamente porque el equilibrio relevante es un equilibrio simétrico de Nash perfecto de subjuego. Por tanto, es útil para estudiar el comportamiento general de los agentes de las redes de narcotráfico.

Se supone que todos los agentes $\mathrm{dDyC}$ tienen el mismo grado en $\mathrm{g}^{D}$. De modo que $d_{j}^{D}=d^{D} \geq 1, \forall j \in N_{D}$. Además, que tienen la misma cantidad de vínculos con narcotraficantes: $d_{j}^{b}=d_{D}^{b} \geq 1, \forall j \in N_{D}$; y que todos los narcotraficantes están conectados con el mismo número de agentes $\mathrm{dDyC}$, de modo que $d_{i}^{b}=d_{T}^{b} \geq 1, \forall j \in N_{T}$. Se puede probar que con redes regulares la condición que establece (4) se cumple en equilibrio de Nash perfecto de subjuego si $p_{0} \cong \frac{2}{\sqrt{c^{D} c_{T}^{b} n_{D}}}$, lo que para valores relativamente grandes de $n_{D} \mathrm{y} \bar{\pi}$ se cumple si $0 \leq p \leq 1$. Así, por sencillez y sin pérdida de generalidad, en lo que sigue se supone que $p_{0}=0,5$. Además, se puede probar que la condición que establece (5) siempre se cumple con redes regulares bajo las hipótesis del modelo, y por parsimonia en lo que sigue también se supone que $\delta=0,5$.

El sistema de equilibrio de Nash perfecto de subjuego ahora se puede expresar así:

$$
w_{1}^{*}=\frac{\bar{\pi}}{4}\left(1-\frac{1}{4} \frac{d^{D}}{\left(n_{D}-1\right)} d_{T}^{b}\left(d_{D}^{b}-1\right) w_{k}\right), k \neq 1
$$

\footnotetext{
${ }^{9}$ Próximos trabajos podrían presentar algunos resultados simulando estructuras no regulares pero estilizadas $\mathrm{de}^{b} \mathrm{y}^{D}$.
} 


$$
\begin{aligned}
& w_{2}^{*}=\frac{\bar{\pi}}{4}\left(1-\frac{1}{4} \frac{d^{D}}{\left(n_{D}-1\right)} d_{T}^{b}\left(d_{D}^{b}-1\right) w_{k}\right), k \neq 2 \\
& w_{n_{T}}^{*}=\frac{\bar{\pi}}{4}\left(1-\frac{1}{4} \frac{d^{D}}{\left(n_{D}-1\right)} d_{T}^{b}\left(d_{D}^{b}-1\right) w_{k}\right), k \neq n_{T}
\end{aligned}
$$

Como los narcotraficantes son homogéneos, en el equilibrio simétrico de Nash $w_{1}^{*}=w_{2}^{*}=\ldots=w_{n_{T}}^{*}=w^{*}$. Resolviendo se obtiene:

$w^{*}\left(c_{D}, c_{T}^{b}, c_{D}^{b}, n_{T}, n_{D}, \bar{\pi}\left(z, P_{D}\right)\right)=\frac{\bar{\pi}}{4+(1 / 4) \bar{\pi} c^{D} c_{T}^{b} \cdot n_{D}\left(c_{D}^{b} n_{T}-1\right)}$

donde $c^{c^{D}}=\frac{d^{D}}{\left(n_{D}-1\right)}$ es la centralidad de grado de los agentes $\mathrm{dDyC}$ en $\mathbf{g}^{D}$, y equivale a la densidad media de $\mathrm{g}^{D}$. El término $c_{T}^{b}=d_{T}^{b} / n_{D}$ corresponde a la centralidad de grado de cada narcotraficante en la red bipartita $\mathrm{g}^{b}$, y capta la densidad media de $\mathrm{g}^{b}$ desde el punto de vista de los narcotraficantes. Por último, el término $c_{D}^{b}=d_{D}^{b} / n_{T}$ corresponde a la centralidad de grado de los agentes dDyC en la red bipartita y capta la densidad media de $\mathrm{g}^{b}$ desde la perspectiva de estos agentes.

El uso de las centralidades de grado simplifica el análisis de estática comparativa, pues las nuevas variables están definidas en los números reales, a diferencia de las variables de grado que son discretas.

\section{ESTÁTICA COMPARATIVA}

1. La ecuación (13) indica que cuanto más grande es la densidad media de las redes, menor es el salario que pagan los narcotraficantes. En el anexo, que se puede consultar en la versión del artículo en la página web de la Revista, se formaliza este resultado mediante la Proposición 1.

a) A medida que los agentes $\mathrm{dDyC}$ tienen más conexiones sociales mutuas entre ellos en $\mathrm{g}^{D}$, menores son los salarios que se les pagan, pues cuanto más (menos) interconectados estén entre sí, mayores (menores) son las externalidades positivas que se generan entre ellos y, en consecuencia, menor (mayor) el costo de su esfuerzo laboral, y mayor (menor) su esfuerzo para un nivel dado de salarios. Como resultado, sus curvas de esfuerzo laboral [dadas por (9)] se desplazan hacia abajo (arriba) y hacia la derecha (izquierda) y los narcotraficantes terminan pagándoles menores (mayores) salarios en el equilibrio, gracias a que son líderes en el juego secuencial. Se puede probar que $w^{*}$ es una función convexa decreciente de $c^{D}$ en equilibrio (gráfica 1$)$. 
Gráfica 1

Salarios de equilibrio en función de $c^{D}$

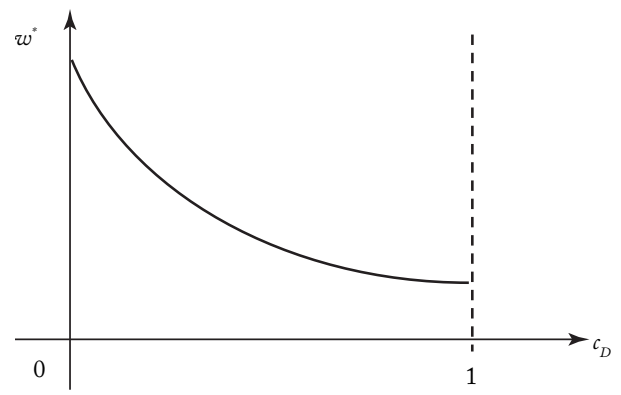

b) Cuanto mayor (menor) es el nivel de conectividad promedio de los narcotraficantes con los agentes dDyC, menores (mayores) son los salarios que pagan. Este impacto se puede pensar como un efecto de competencia. Cuantos más agentes dDyC puede contratar potencialmente un narcotraficante, debido a que tienen vínculos sociales con él, mayor es su disponibilidad de mano de obra y, por tanto, mayor es su poder de mercado y de negociación frente a ellos, por lo que termina pagando menores salarios. Se puede probar que w" también es una función convexa decreciente de $c_{T}^{b}$ en equilibrio. La gráfica es similar a la anterior.

c) Cuanto mayor es el nivel de conectividad promedio de un agente $\mathrm{dDyC}$ con los narcotraficantes, menor es el salario que devenga, porque para cada narcotraficante la letalidad aumenta cuando un mismo empleado trabaja para más narcotraficantes, y esto tiene un efecto negativo en su probabilidad de supervivencia. Aunque se podría pensar que una mayor conectividad de un agente $\mathrm{dDyC}$ con los narcotraficantes debería inducir una mayor demanda relativa de mano de obra y por ello mayores salarios, el impacto letal de la mayor conectividad de los agentes $\mathrm{dDyC}$ con otros narcotraficantes invierte esta relación. El salario también es una función convexa decreciente de $c_{D}^{b}$ en equilibrio; la gráfica es similar a la gráfica 1.

2. La ecuación (13) también muestra que el tamaño de las redes de defensa y corrupción incide en el salario de equilibrio. Los efectos de cambios de $n_{D}$ y $n_{T}$ son similares a los de $c_{T}^{b}$ y $c_{D}^{b}$ y por ello no se analizan. El análisis prosigue entonces con $w^{*} \equiv w^{*}\left(c_{D}, c_{T}^{b}, c_{D}^{b}, \pi\left(z, P_{D}\right)\right)$.

3. Se puede probar que un aumento (reducción) del beneficio neto de la producción de drogas (sin descontar los costos de defensa y corrupción), $\bar{\pi}$ provocado por un aumento del precio de la droga 
aumenta (reduce) los salarios que pagan los narcotraficantes (ver la prueba en el anexo).

Una mayor rentabilidad neta del negocio genera incentivos para que los narcotraficantes demanden mayor cantidad de trabajo para mantener sus aparatos de defensa y corrupción. Como resultado, los salarios de equilibrio que pagan a los agentes $\mathrm{dDyC}$ tienden a subir, es decir, hay una relación directa entre el precios de la droga y los salarios que pagan los narcotraficantes a estos agentes; debido al impacto positivo de un aumento de precios sobre los beneficios netos de la producción de drogas ilegales, $\bar{\pi}$. Además, se puede probar que $w^{*}$ es una función cóncava de $\bar{\pi}$ (gráfica 2); por tanto, los salarios también son una función cóncava de los precios.

Gráfica 2

Salarios de equilibrio en función de $\bar{\pi}$

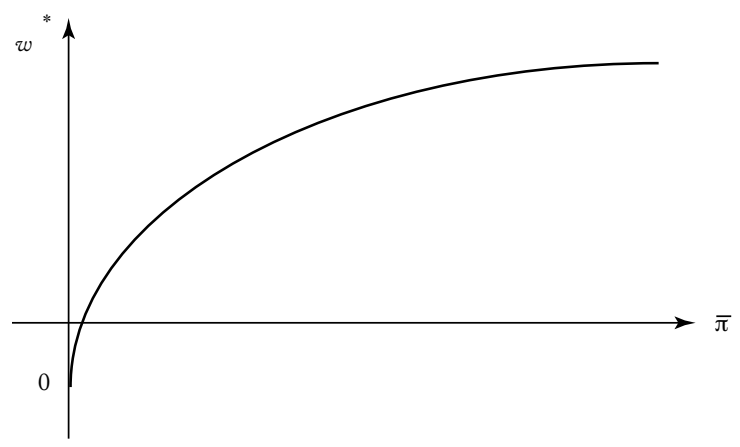

4. El fortalecimiento de la política de represión de las drogas -captado por un aumento de la probabilidad de interdicción y detección-induce una baja en los salarios de equilibrio (ver la prueba en el anexo). Este efecto obedece al impacto de un mayor valor de $z$ sobre $\bar{\pi}$. Debido a la concavidad de los salarios con respecto a $\bar{\pi}$, son una función cóncava decreciente de $z$.

Sustituyendo (13) en (9) se obtiene el nivel de esfuerzo de equilibrio de cualquier agente $\mathrm{dDyC}$ :

$e^{*}=\frac{(1 / 2) \bar{\pi} c^{D}}{4+(1 / 4) \bar{\pi} c^{D} c_{T}^{b} n_{D}\left(c_{D}^{b} n_{T}-1\right)}$

teniendo en cuenta (13) e $e^{*}$ se puede escribir simplemente así:

$e^{*}=\frac{c^{D} w^{*}}{2}$ 
Como era de esperar, el nivel de esfuerzo de equilibrio de Nash de cualquier agente $\mathrm{dDyC}$ depende en forma directa del salario de equilibrio devengado. Por consiguiente, depende en forma inversa de $c_{D}^{b} \mathrm{y}$ de $c_{T}^{b}$ La incidencia de la densidad media de $\mathrm{g}^{D}$ en $e^{*}$ es doble: $c_{D}$ influye inversamente a través de su impacto en $w^{*}$, y tiene un efecto directo en esta variable; no obstante, el efecto neto es positivo (ver la prueba en el anexo).

Gráfica 3

Esfuerzo de equilibrio en función de $c^{D}$

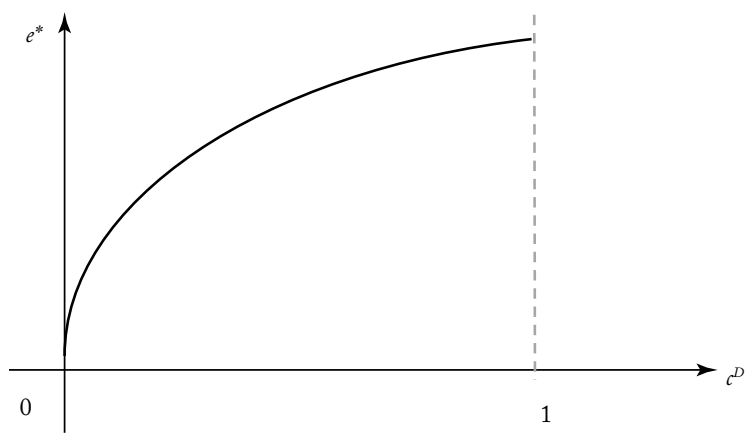

Esta relación muestra la importancia de la densidad de las interconexiones de los agentes dDyC. A pesar del efecto negativo de $c_{D}$ en $w^{*}$, el impacto de las externalidades en red que producen los vínculos entre los agentes $\mathrm{dDyC}$ es un determinante central de su actividad criminal. Este resultado es consistente con diversos trabajos sobre criminología (Sutherland, 1947), sociología del crimen y economía del crimen, que muestran la importancia de las redes sociales en las actividades criminales ${ }^{10}$. En economía del crimen, Calvó-A. y Zenou (2004) y Ballester et al. $(2006,2009)$ prueban la incidencia positiva de las interacciones locales y los efectos de derrame (peer effects) en las actividades delincuenciales.

Sustituyendo (14) en (3) se obtiene la probabilidad de supervivencia de equilibrio de un narcotraficante:

$p^{*}=\frac{c^{D} c_{T}^{b} n_{D} \bar{\pi}}{\left[4+(1 / 4) \bar{\pi} c^{D} c_{T}^{b} n_{D}\left(c_{D}^{b} n_{T}-1\right)\right]^{2}}$

o, lo que es lo mismo:

$p^{*}=\frac{c^{D} c_{T}^{b} n_{D} w^{* 2}}{\bar{\pi}}$

${ }^{10}$ Ver Hagedorn (1988), Padilla (1992) y Levitt y Venkatech (2000), entre otros. 
5. Estas ecuaciones indican que unas redes de defensa y corrupción más densas llevan inevitablemente a que los narcotraficantes enfrenten menor probabilidad de supervivencia y, por ello, a la configuración de tecnologías $\mathrm{pCyC}$ más inseguras y letales a la vez. La mayor densidad de las redes debilita los sistemas de seguridad de cada narcotraficante, $\mathrm{y}$ al mismo tiempo mejora su capacidad para emprender acciones ofensivas contra sus rivales, que suelen ser planeadas por los traficantes pero perpetradas por sus agentes $\mathrm{dDyC}$. Veamos por qué.

a) El aumento del nivel de conectividad de los agentes $\mathrm{dDyC}$ con los narcotraficantes, es decir, de la densidad media de $\mathrm{g}^{b}$ desde la perspectiva de los agentes $\mathrm{dDyC}$, reduce la probabilidad de supervivencia de estos últimos (ver la Proposición 5 en el anexo). Se puede probarse que $p^{*}$ es una función convexa decreciente de $c_{D}^{b}$ (gráfica 4):

Gráfica 4

Probabilidad de supervivencia en función de $c_{D}^{b}$

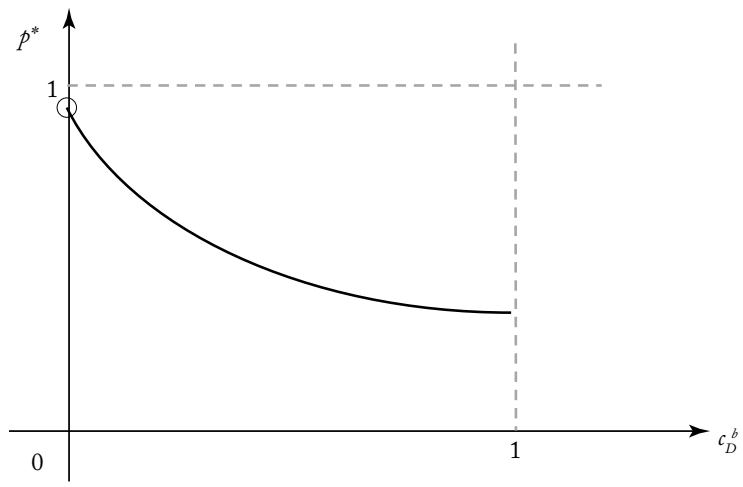

Este resultado obedece a que la probabilidad de supervivencia de un narcotraficante depende de los vínculos de sus empleados con otros narcotraficantes: cuantas más (menos) conexiones tienen sus hombres con otros narcotraficantes, menor (mayor) es su probabilidad de supervivencia.

b) En redes relativamente densas, aumentos (reducciones) de las interconexiones entre los agentes $\mathrm{dDyC}$, es decir, en la densidad media de $\mathrm{g}^{D}$, llevan a reducciones (aumentos) de $p^{*}$. Ocurre lo contrario en redes con una densidad relativamente baja (ver la prueba de la Proposición 6 en el anexo). Se puede probar que $p *$ es un función cóncava creciente de $c_{D}$ (gráfica 5).

Este resultado muestra que los cambios en $c^{D}$ producen dos tipos de efectos sobre la probabilidad de supervivencia de un narcotrafi- 
cante: un efecto directo que capta la incidencia positiva de un aumento de esa variable sobre el nivel de esfuerzo realizado por sus hombres (ver el primer término a la derecha de la ecuación A8 del anexo); $\mathrm{y}$ un efecto indirecto negativo sobre los salarios de equilibrio, el cual afecta el esfuerzo de sus propios hombres y el de los empleados de otros narcotraficantes (ver el segundo término de la derecha de la ecuación A8 del anexo). El impacto neto de los cambios en $c^{D}$ sobre $p^{*}$ será positivo o negativo dependiendo de cuán fuertes sean estos dos efectos; su fortaleza depende del nivel de densidad de las redes, que determina el nivel de letalidad de la tecnología $\mathrm{pCyC}(\ell)$ (ver la definición 1 del anexo).

\section{Gráfica 5}

Probabilidad de supervivencia en función de $c_{D}$

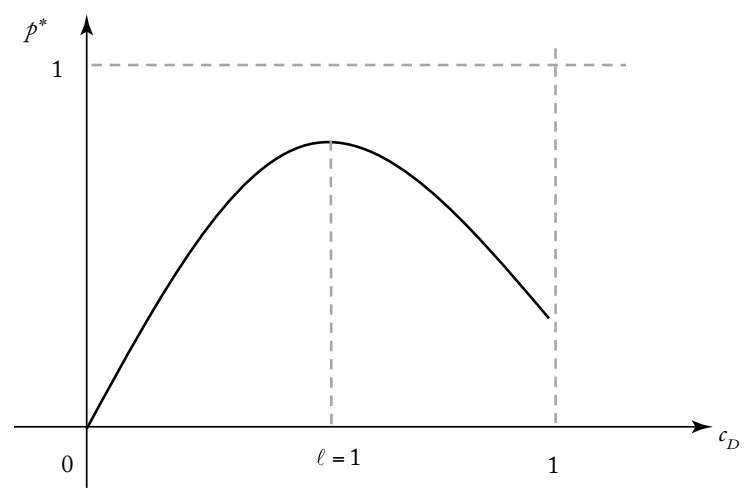

Para bajos niveles de densidad de las redes y de letalidad de la tecnología $(\ell<1)$ es más fuerte el efecto directo, y $\frac{d p^{*}}{d c^{D}}>0$. En la gráfica, este caso corresponde a puntos de $c^{D}$ a la izquierda del máximo de $p^{*}$, punto en que $\ell=1$. Sucede lo contrario en redes más densas y altos niveles de letalidad de la tecnología $(\ell<1): \frac{d p^{\prime \prime}}{d c^{D}}<0$. En la gráfica, este caso corresponde a puntos de $c^{D}$ a la derecha del máximo de $p^{*}$. Solo en redes con un nivel de densidad intermedio y tecnologías $\mathrm{pCyC}$ con un nivel de letalidad moderado $(\ell=1) \frac{d p^{*}}{d c^{D}}=0$.

c) En redes relativamente densas y, por ende, tecnologías $\mathrm{pCyC}$ con altos niveles de letalidad, aumentos (reducciones) de las conexiones de los narcotraficantes con los agentes $\mathrm{dDyC}$ en la red bipartita $\left(\mathrm{g}^{b}\right)$ dan lugar a reducciones (aumentos) de la probabilidad de supervivencia de los narcotraficantes. Ocurre lo contrario en redes con una densidad relativamente baja y, por ende, tecnologías $\mathrm{pCyC}$ con bajos niveles de letalidad (ver la prueba de la Proposición 7 en el anexo). Se puede 
probar que $\frac{d^{2} p^{*}}{d c_{T}^{*}}<0$ Por tanto, $p^{*}$ es una función cóncava de esta variable. La gráfica es similar a la anterior. La explicación de este resultado es análoga a la del efecto de cambios en $c^{D}$ sobre $p^{*}$.

6. Se puede probar que un aumento (reducción) del beneficio neto de la producción de drogas $\left(\bar{\pi}=(1-z) \cdot P_{D} \cdot q-s l\right)$ debido a un aumento de su precio lleva a un aumento o a una reducción de $p^{*}$ dependiendo del nivel de densidad de las redes y de la letalidad de la tecnología pCyC (ver la prueba de la Proposición 8 en el anexo). En redes con bajos niveles de densidad y de letalidad $(\ell<1)$ un aumento de $P_{D}$ jalona un incremento de $p^{*}$. Ocurre lo contrario en redes con alto nivel de densidad y, por ello, de letalidad. Se puede probar que $p^{*}$ es una función cóncava de $P_{D}$.

Un efecto similar produce un incremento en el beneficio neto de la producción de drogas causado por incrementos en las ventas o por bajas en los costos de la mano de obra empleada en la parte productiva de la cadena.

Este análisis es esencial para entender que los auges de estos negocios ilegales, provocados por aumentos de la demanda, pueden intensificar las acciones violentas de los narcotraficantes entre sí, lo que a la postre autorregula esas actividades ilícitas. Esto explica por qué durante los años noventa en los carteles de Medellín y de Cali hubo guerras internas en épocas de auge, que en parte llevaron a su autodestrucción, y a su desmantelamiento por las agresivas políticas de represión de las autoridades.

7. También se puede probar que una reducción (aumento) del beneficio neto de la producción de drogas generado por un aumento (reducción) de la probabilidad de interdicción y destrucción, $z$, reduce o aumenta $p$ dependiendo de la densidad de las redes y de la letalidad de la tecnología pCyC (ver la prueba de la Proposición 9 en el anexo). Como $p$ es una función cóncava de $\bar{\pi}$ también es una función convexa decreciente de $z$ (gráfica 6).

La explicación de este resultado es análoga a la del anterior. También depende del impacto de un cambio de $z$ sobre $\bar{\pi}$ pero en este caso un aumento (reducción) de $z$ lleva a una reducción (aumento) de $\bar{\pi}$.

Por limitaciones de espacio no se presenta la solución ni el análisis de las ganancias de equilibrio de los dos tipos de agentes. No obstante, cabe mencionar que la densidad de las redes incide en las ganancias esperadas de los narcotraficantes así como determinan su probabilidad de supervivencia. La densidad tiene un efecto análogo sobre las ganancias de los agentes $\mathrm{dDyC}$. El impacto de los parámetros de las redes sobre las ganancias efectivas de los narcotraficantes es 
contrario al que tienen sobre sus ganancias esperadas. El aumento de la probabilidad de interdicción y destrucción de las drogas lleva siempre a una reducción de las ganancias esperadas de los narcotraficantes y de los agentes $\mathrm{dDyC}$. No obstante, dependiendo del valor de la elasticidad de los salarios a cambios en esta variable, pueden inducir aumentos de las ganancias efectivas de los narcotraficantes. Por ello, si las redes de defensa y corrupción son relativamente densas y la tecnología $\mathrm{pCyC}$ tiene alto nivel de letalidad, una mayor represión de la oferta de drogas puede llevar al resultado paradójico de una mayor probabilidad de supervivencia de los narcotraficantes que lideran la organización, e incluso a que obtengan mayores ganancias efectivas.

Gráfica 6

Probabilidad de supervivencia en función de $z$

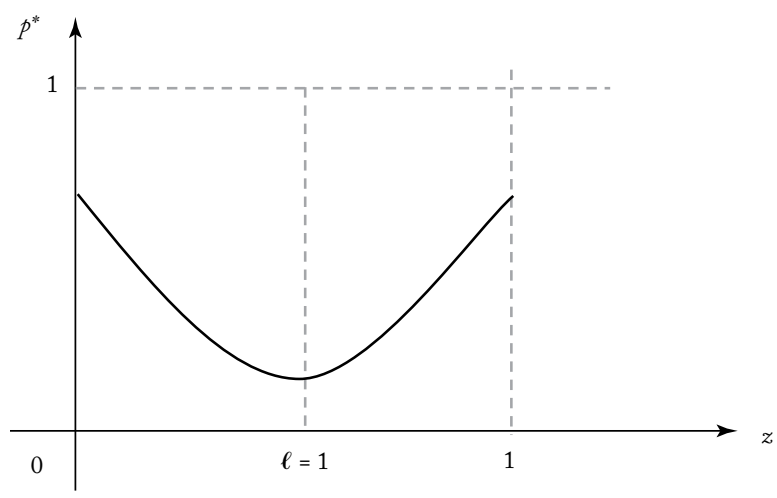

\section{ALGUNAS PREDICCIONES DEL MODELO}

A pesar de las características estilizadas del modelo con redes regulares, su solución ayuda a entender la evolución de las redes del narcotráfico en Colombia desde comienzos de los años ochenta, y por qué a pesar de la fuerte represión ejercida en los principales países productores y consumidores en la guerra contra las drogas, las organizaciones ilegales se han reproducido y multiplicado, garantizando el abastecimiento de la demanda mundial. No obstante el estancamiento de la demanda de heroína y cocaína durante las dos últimas décadas y la caída de las utilidades repatriables o ingresos netos (como porcentaje del PIB) de los narcotraficantes (Rocha, 2000, 2014; Steiner y Corchuelo, 1999).

El modelo revela algunos hechos importantes:

1. Con la escalada de la confrontación entre los grandes carteles desde finales de los años ochenta, y su desmantelamiento a mediados de la década siguiente, la densidad de las redes de defensa y corrupción 
creció paulatinamente a medida que los agentes encargados de estas actividades creaban más vínculos entre sí y con otros narcotraficantes. Como resultado, la mano de obra especializada se hizo más móvil y las tecnologías $\mathrm{pCyC}$ tendieron a hacerse más letales, dando lugar inicialmente a un aumento progresivo de la probabilidad de supervivencia de los narcotraficantes, y luego a reducciones progresivas.

En la mitad de los noventa estas tendencias se reforzaron y llevaron a una expansión del crimen organizado (Rocha, 2012). ¿Cómo es posible entonces que el resultado de este proceso no haya desembocado en la destrucción de la mayoría de las organizaciones y, por tanto, a una reducción definitiva de las actividades ilegales?

2. La clave para responder esta pregunta es la ineficacia de las políticas de represión de la oferta en todo el periodo. El modelo da luces a ese respecto: una mayor represión de las drogas, captada por una mayor probabilidad de interdicción y destrucción de las drogas, lleva a que los narcotraficantes bajen los salarios que pagan a los agentes dDyC. Por ello, a niveles relativamente bajos de densidad de las redes de defensa y corrupción y, por ende, de letalidad de la tecnología pCyC, el aumento de la probabilidad de interdicción y destrucción de las drogas, ceteris paribus, reduce la probabilidad de supervivencia de equilibrio de los narcotraficantes. Ocurre lo contrario cuando las redes son relativamente densas y la tecnología es más letal, como sucedió durante la mayor parte de los noventa y al menos la primera mitad de la pasada década.

Por esa razón, la política de represión a la drogas es más efectiva en el primer caso, porque reduce la probabilidad de supervivencia de los narcotraficantes. Esto impulsa las tendencias autodestructivas siempre presentes en una red criminal. Esta política es menos efectiva en el segundo caso, porque aumenta inevitablemente la probabilidad supervivencia de los narcotraficantes, lo que genera tendencias revitalizadoras en el sistema, que garantizan el predominio de los capos de turno en el corto y en el mediano plazos. Estas tendencias forman un mecanismo de autorregulación que evita la fluctuación extrema de la probabilidad de supervivencia de los narcotraficantes y, por ende, de los niveles de letalidad.

3. El modelo corrobora la existencia de una relación directa entre los salarios y los precios de la droga. Aunque los precios se suponen dados, si se relaja este supuesto y se supone que los precios son afectados por cambios en los salarios, se tiene una explicación del 
descenso promedio en el largo plazo de los precios de la cocaína y la heroína durante las tres últimas décadas (Caukins y Reuter, 2010; Raffo, 2010) ${ }^{11}$ : el aumento de la densidad de las redes de defensa y corrupción propiciado por la entrada de más personas al negocio, debido a la globalización de las actividades ilícitas y a la aparición de estructuras ilegales más atomizadas pero con mano de obra más móvil y abundante, especializada en las labores de defensa y corrupción, puede ser clave para entender la baja de los salarios de la mano de obra empleada en toda la cadena. Esto es consistente con la explicación de Costa y de Grauwe (2009a, 2009b) sobre la baja de precios de las drogas duras durante las últimas décadas, y con los argumentos de Poret y Téjedo (2006) sobre la evolución de las estructuras de los mercados ilegales.

4. Lo anterior explica por qué las políticas de represión de las drogas aplicadas durante varias décadas no elevaron sus precios, como predice la teoría ${ }^{12}$. A pesar de la contracción de la oferta inducida por la represión y del aumento de precios que provoca en el corto plazo, la baja de salarios como reacción estratégica de los narcotraficantes puede neutralizar e invertir esta tendencia. Este fenómeno, sumado al aumento de mediano plazo en la densidad de las redes que se presentó en los años noventa y parte de la pasada década, explica las reacciones estratégicas de los narcotraficantes que provocan nuevas expansiones de los negocios ilícitos y la producción de drogas ilícitas, que llevan inevitablemente a reducciones de precios de las drogas duras, a pesar de las políticas de represión. Este mecanismo explica el funcionamiento del efecto hidra al que hacen alusión otros trabajos (Ortiz, 2002, 2003, 2009) a nivel microeconómico.

5. Aunque el aumento de la probabilidad de interdicción y destrucción de las drogas siempre lleva a bajas de las ganancias esperadas de los narcotraficantes y de las ganancias de los agentes dDyC, dependiendo de la elasticidad de los salarios a cambios en esta variable, eventualmente puede aumentar sus ganancias efectivas. Esto refuerza el argumento expuesto en el punto anterior. Si las redes de defensa y corrupción son relativamente densas y la tecnología tiene alto nivel de letalidad, una mayor represión de la oferta de drogas puede llevar al resultado paradójico de una mayor probabilidad de supervivencia de los narcotraficantes que lideran la organización, e incluso a que obtengan mayores ganancias efectivas.

${ }^{11}$ Ver también Costa y de Grauwe (2009a, 2009b), Poret y Téjedo (2006), Mejía y Posada (2007) y Miron (2001).

${ }_{12}$ Ver Becker et al. (2006), Ortiz (2002, 2003, 2009), Poret y Téjedo (2006), y Caulkins y Reuter (2010).

Revista de Economía Institucional, vol. I7, N.o 32, PRimer Semestre/20i5, Pp. I83-2I 2 


\section{CONCLUSIONES}

$\mathrm{E} 1$ análisis de las redes que soportan el funcionamiento de las actividades del narcotráfico es esencial. No es posible entender la operación de la economía del narcotráfico en un contexto dado sin estudiar la estructura y la evolución de las redes sociales que apoyan sus actividades. Estas redes son de dos tipos: las de producción y tráfico de drogas, que crean las bases sociales para el funcionamiento y reproducción de una tecnología de producción y tráfico; y las de defensa y corrupción, que crean las bases sociales para el funcionamiento de una tecnología para el conflicto y la corrupción.

E1 modelo teórico propuesto ayuda a entender las interacciones estratégicas que ocurren en las redes del narcotráfico y, en particular, en sus redes de defensa y corrupción. Se probaron varios resultados importantes: 1) la densidad de estas redes es un determinante esencial de los salarios que los narcotraficantes pagan a sus agentes $\mathrm{dDyC}$ : redes más densas llevan a pagar menores salarios, por el impacto de la mayor densidad en la competencia y la eficiencia productiva en las relaciones laborales; 2) aparte del salario, un determinante esencial del nivel de esfuerzo de los agentes dedicados a la seguridad y a las actividades de corrupción al servicio de los narcotraficantes son sus vínculos sociales mutuos, debido a las externalidades positivas que generan. Esto corrobora los análisis de Calvó-A. y Zenou (2004) y Ballester et al. (2006, 2009), entre otros autores, que prueban la incidencia positiva de las interacciones locales y los efectos de derrame en las actividades delictivas; 3) la probabilidad de supervivencia de los narcotraficantes depende esencialmente de la estructura de las redes de defensa y corrupción y, en particular, de su densidad media; 4) a pesar de que los precios son una variable exógena, el modelo corrobora que hay una relación directa entre salarios y precios de la droga.

Por último, el modelo también da nuevas luces sobre los efectos de las políticas de represión de la oferta de drogas. La eficacia y los efectos de la política anti drogas dependen de la estructura de las redes al servicio del narcotráfico: cuando cambian súbita o progresivamente las estructuras de las redes, los narcotraficantes reaccionan estratégicamente modificando el pago a los agentes de las redes $\mathrm{dDyC}$ para adaptarse a las condiciones desfavorables. Como resultado, se reacomoda todo el sistema de defensa y corrupción que garantiza la supervivencia global de sus organizaciones, aunque algunas desaparecen, otras mutan y surgen algunas nuevas. 
Retomando la metáfora de la hidra, este artículo muestra que su existencia está íntimamente ligada al funcionamiento de sus tentáculos de violencia. Se pueden atacar sus cabezas, apoyadas en las estructuras de producción y tráfico, pero el monstruo sobrevive si no se rompen esos tentáculos. La actividad ilegal tiene una gran capacidad para mutar y expandir sus tentáculos. La represión de las drogas centrada en la erradicación y la interdicción puede tener éxito local para combatir drogas específicas, pero no quebranta las redes violentas que soportan las actividades ilegales. Por ello la reducción de la producción de cocaína en Colombia durante los últimos años ha llevado también a la expansión de otras actividades ilegales: la minería ilegal, la extorsión y el contrabando. Y esto ha sido posible por la existencia y el funcionamiento de tecnologías de violencia y corrupción y de las redes sociales que las soportan.

Los anexos se pueden consultar en la página web de la revista.

\section{REFERENCIAS BIBLIOGRÁFICAS}

1. Becker, G. S.; K. Murphy y M. Grossman. "E1 mercado de bienes ilegales: el caso de la droga", Revista de Economía Institucional 8, 15, 2006, pp. 17-42.

2. Ballester, C.; A. Calvó-A. y Y. Zenou. "Delinquent networks", IZA discussion paper, Series 4112, 2009, pp. 1-43.

3. Ballester, C.; A. Calvó-A. y Y. Zenou. "Who's who in networks. Wanted: The key player", Econometrica 74, 5, 2006, pp. 1403-1417.

4. Calvó-A., A. y Y. Zenou. "Social networks and crime decisions: The role of social structure in facilitating delinquent behavior", International Economic Review 45, 3, 2004, pp. 939-958.

5. Cartay, R. “Control de la cocaína: ¿represión o legalización?”, Revista de Economía 9, 1994, pp. 7-14.

6. Caulkins, J. P. y P. Reuter. "How drug enforcement affects drug prices?”, Crime and Justice 39, 1, 2010, pp. 213-271.

7. Costa S., C. y P. de Grauwe. "Globalization and the price decline of illicit drugs", International Journal of Drug Policy 20, 2009a, pp.48-61.

8. Costa S., C. y P. de Grauwe. "The cocaine and heroin markets in the era of globalization and drug reduction policies", International Journal of Drug Policy 20, 6, 2009b, pp.488-496.

9. Duncan, G. 2005. "Narcotraficantes, y mafiosos y guerreros. Historia de una subordinación", A. Rangel, ed., Narcotráfico en Colombia: economia y violencia. Bogotá, Fundación Seguridad y Democracia, 2004.

10. Garay L. J. y E. Salcedo-A. 2012. Narcotráfico, corrupción y Estados, Bogotá, Nomos, 2002.

11. Hagedorn, J. People and folks: Gangs, crime and the underclass in a rustbelt city, Chicago, Lake View Press, 1988.

12. Hellman, J.; G. Jones y D. Kaufmann. "Seize the day: State capture, corruption and influence in transition", Washington, World Bank, 2000. 
13. Hellman, J. y D. Kaufmann. "Intervention, corruption and capture: The nexus between enterprises and the state", European Bank for Reconstruction and Development, 2000.

14. Hellman, J. y D. Kaufmann. "La captura del Estado en las economías de transición", Finanzas y Desarrollo 38, 3, 2001, pp. 31-35.

15. Krauthausen, C. y L. F. Sarmiento. Cocaina E Co. Un mercado ilegal por dentro, Bogotá, Tercer Mundo-IEPRI, 1991.

16. Lazear, E. y S. Rosen. "Rank-order tournaments as optimum labor contracts", Journal of Political Economy 89, 1981, pp. 841-64.

17. Levitt, S. D. y S. A. Venkatesh. "An economic analysis of a drugselling gang's finances”, Quarterly Journal of Economics 115, 3, 2000, pp. 755-789.

18. Martín, D. "E1 narcotráfico como fuente de trabajo informal”, VI Congreso Portugués de Sociología, Universidad Nova de Lisboa, 2008, http://www.aps.pt/vicongresso/pdfs/453.pdf].

19. Mejía, D. y H. Grossman. “The war against drug producers”, NBER working papers series 11141, 2005, pp. 1-24.

20. Mejía, D. y C. E. Posada. "Cocaine production and trafficking: What do we know?", Borradores de Economía 444, 2007, pp. 1-53.

21. Mejía, D. y P. Restrepo. "The war on illegal drug production and trafficking: An economic evaluation of Plan Colombia", Documentos CEDE 19, 2008.

22. Mejía, D. y D. Rico. “La microeconomía del tráfico y la producción de cocaína en Colombia”, A. Gaviria y D. Mejía, eds. Politicas antidroga en Colombia: éxitos, fracasos y extravios, Bogotá, Universidad de los Andes, 2011.

23. Miron, J. "The effect of drug prohibition on drug prices: Theory and evidence", Boston University y Bastiat Institute, 2001.

24. Observatorio del Programa Presidencial de Derechos Humanos y Derecho Internacional Humanitario, "Dinámica reciente de la violencia en el norte del Valle”, Bogotá, 2006, [www.derechoshumanos. gov.co/observatorio].

25. Ortiz, C. H. "Luchando infructuosamente contra la hidra: un modelo sencillo del narcotráfico", Cuadernos de Economía 37, 2002, pp. 139-159.

26. Ortiz, C. H. "La guerra contra las drogas es contraproducente: un análisis económico de equilibrio general”, Lecturas de Economía 58, 2003, pp. 47-68.

27. Ortiz, C. H. "The war on drugs is counterproductive, once again", Lecturas de Economía 71, 2009 pp. 19-42.

28. Padilla, F. The gang as an American enterprise, New Brunswick, Rutgers University Press, 1992.

29. Poret, S. y C. Téjedo. "Law enforcement and concentration in illicit drug markets", European Journal of Political Economy 22, 2006, pp. 99-114.

30. Raffo, L. "Narcotráfico y conflicto: por qué bajó el precio de la cocaína", Revista de Economía Institucional 12, 23, 2010, pp. 229-258.

31. Rocha, R. La economia colombiana tras 25 años de narcotráfico, Bogotá, Siglo del Hombre-UNDC, 2000. 
32. Rocha, R. Las nuevas dimensiones del narcotráfico en Colombia, Bogotá, UNOCD-Ministerio de Justicia y del Derecho, 2011.

33. Rocha, R. "La riqueza del narcotráfico y la desigualdad en Colombia: 1976-2012”, Archivos de Economía 417, DNP, 2014.

34. Salazar, B. y L. Restrepo. "Intimidades letales: la evolución de una red de tráfico de droga local”, Desafíos 23, 2, 2011, pp. 197-222.

35. Sarmiento, E. "Economía del narcotráfico", C. G. Arrieta et al., Narcotráfico en Colombia: dimensiones politicas, económicas, jurídicas e internacionales [1990], Bogotá, Tercer Mundo-Uniandes, 1995.

36. Silva de S. R. "Narcotráfico y economía ilícita: las redes del crimen organizado en Río de Janeiro", Revista Mexicana de Sociología 66, 1, 2004, pp.141-164.

37. Steiner, R. y A. Corchuelo. "Repercusiones económicas e institucionales del narcotráfico en Colombia", Ensayos sobre Economia Cafetera 15, 1999.

38. Sutherland, E. H. Principles of criminology, $4^{\text {th }}$ edition, Chicago, J. B. Lippincott.

39. Tickner, A. B.; D. García y C. Arreaza. "Actores violentos no estatales y narcotráfico en Colombia”, A. Gaviria y D. Mejía, eds., Politicas antidroga en Colombia: éxitos, fracasos y extravios, Bogotá, Universidad de los Andes, 2011.

40. UNOCD. "Result of a pilot survey of forty selected organized criminal groups in sixteen countries”, Global Programme against Transnational Organized Crime, 2002, [http://www.unodc.org/pdf/crime/publications/Pilot_survey.pdf].

41. UNODC. World drug report, Nueva York, 2012, 2013, 2014.

42. Williams, P. "Drug trafficking networks", Current history, 1998, pp. 154-159.

43. Williams, P. “Transnational criminal networks”, J. Arquilla y D. Ronfeldt, eds., Networks and netwars: The future of terror, crime and militancy, Santa Monica, RAND Corporation, 2001. 